\title{
Reivindicación del espíritu rebelde. La crítica de Simone Weil al concepto tradicional de revolución.
}

\author{
Vindication of the rebellious spirit. Simone Weil's criticism of the \\ traditional concept of revolution.
}

Esta obra está bajo una Licencia Creative Commons Atribución 4.0 Internacional. DOI: $10.32870 /$ sincronia.axxii.n74.4b18

\author{
Anakaren Monserrat Rojas Cuautle* \\ Instituto de Investigaciones Filosóficas "Luis Villoro" / Universidad Michoacana de San Nicolás de \\ Hidalgo \\ cuautle_nerak_@hotmail.com \\ (MÉXICO)
}

Recibido: $14 / 03 / 2018$

Revisado: 20/03/2018

Aprobado: 23/05/2018

* Nota del autor: Maestra en filosofía, actualmente cursa el cuarto semestre del doctorado en la misma disciplina en la Universidad Michoacana de San Nicolás de Hidalgo.

\section{RESUMEN}

En 1933, Simone Weil estudia la situación social de Rusia. Para ella, el régimen socialista no estaba cumpliendo su objetivo principal, la liberación de los obreros. Por esta razón, la filósofa francesa analiza el concepto tradicional de revolución. Esta palabra carece de contenido, es un concepto lleno de imaginarios colectivos por el cual se ha derramado sangre valiosa. En el texto señalaremos cuáles son los problemas de la revolución, la crítica de Weil hacia Marx, así como el problema principal que, según la pensadora, debe enfrentar el revolucionario para realizar un verdadero cambio social.

Palabras clave: Revolución. Trabajo. Marx. Fábrica. Trabajadores.

\section{ABSTRACT}

In 1933, Simone Weil studied the social situation in Russia. For her, the socialist regime was not fulfilling its main objective, the liberation of the workers. For this reason, the philosopher analyzes the traditional concept of revolution. This word lacks content, it is a concept full of collective imaginaries through which valuable blood has been spilled. In this paper, we will indicate which are 
the problems of the revolution, Weil's criticism of Marx, as well as the main problem that, according to the philosopher, the revolutionary must face in order to realize a true social change.

Keywords: Revolution. Work. Marx. Factory. Workers.

\section{Desarrollo}

\section{I) Nada en el mundo puede impedirnos ser lúcidos}

En octubre de 1917, una revuelta social cambió el rumbo no solo de un país sino del mundo entero. Se instaló, por primera vez en la historia de la humanidad, un régimen que tenía como propósito principal erradicar por completo la opresión en la que vivían los trabajadores, colectivizar los medios de producción, igualar las condiciones de los obreros y así, poder instaurar en una sexta parte del globo terráqueo, el reino de la libertad.

Con la instauración del régimen socialista, el capitalismo recibió una estocada que puso en peligro su existencia. La fiebre anticapitalista se extendió en toda Europa en forma de Partidos Socialistas y Comunistas, los cuales quedaron a merced de las indicaciones de Rusia. La caída del capitalismo, se repetía por todas partes, es solo cuestión de tiempo.

Después de la muerte de Lenin y con Stalin en el poder, el "fin del capitalismo" pasó de ser una verdad incuestionable, a un mito. Sin embargo, pocos revolucionarios denunciaban esta cuestión, las mentiras sobre una revolución inminente se seguían contando como los cuentos infantiles que se les recitan a los pequeños antes de dormir. Pronto llegará la revolución, se les repetían a los obreros en incontables ocasiones. Incluso el mismo Trotsky se negaba a aceptar la inexistencia del socialismo en Rusia, para él, el Estado ruso era un Estado obrero con deformaciones burocráticas.

Dieciséis años después de que la bandera roja ondeara en el Palacio de Invierno, una joven mujer invadida por el coraje que causa la injusticia social y con el deber principal de no mentir-se a sí misma ni a los demás, escribe un artículo en el que se cuestionan los aparentes "logros" del Estado Ruso, el objetivo es develar el vacío que se encuentra en ese dios al que los socialistas adoran ciegamente: la Revolución. 
Simone Weil, una pensadora francesa que había egresado de la Escuela Normal Superior dos años antes, escribe en 1933 el artículo Perspectivas ${ }^{1}$ para la revista La Révolution prolétarienne; el texto comienza con un epígrafe de Sófocles que resume maravillosamente el propósito de la autora: “No tengo más que desprecio por el mortal que cobra ánimos con esperanzas vanas" (Weil, 2007, p. 80). El status quo de la Revolución Rusa se definía una y otra vez con la misma palabra, transición. Pero ¿transición hacia dónde? pregunta Weil; se piensa que el socialismo llegará pasado mañana y mientras: "se vaya entendiendo por pasado mañana dos días después del presente, se puede estar seguro que nunca será desmentido, pero ese estado mental poco se diferencia de las buenas gentes que creen, por ejemplo, en el Juicio Final" (p. 80).

El régimen que nació en octubre del 17 tenía una misión clara, propagar la lucha del proletariado a nivel mundial y, sin embargo, como sucedió en Alemania, solo ha ahogado eso intentos ${ }^{2}$; de igual manera, la situación de los obreros y de la población civil en Rusia es lamentable. La descripción que hace Weil es desgarradora:

A decir verdad, ese régimen recuerda al que creía instaurar Lenin en la medida que excluye casi completamente la propiedad capitalista; en cuanto al resto es exactamente lo contrario. En lugar de una libertad efectiva de prensa, la imposibilidad de expresar un juicio libre en la forma de documento impreso [...] sin arriesgarse a la deportación; en lugar del libre juego de los partidos en los marcos del sistema soviético, "un partido en el poder, y los demás en la cárcel"; en lugar de un partido comunista [...] una simple maquinaria administrativa, instrumento pasivo en manos del secretariado, y que, a decir

\footnotetext{
${ }^{1}$ La editorial colocó el subtítulo ¿Vamos a la revolución proletaria?

${ }^{2}$ En 1932 Weil viaja a Alemania para averiguar en qué se basa la fuerza del fascismo, analizando la situación del país, concretamente la posibilidad de una revolución proletaria. Escribe una serie de artículos sobre esta experiencia que se publican en revistas como La Révolution Prolétarienne o L'École émancipée (en algunos casos la redacción se niega a publicar partes de los textos). La conclusión a la que llega la pensadora francesa es preocupante: el Partido Comunista Alemán ahoga la posibilidad de una revolución proletaria, pues éste se encuentra compuesto de hombres "privados de cualquier función productora, expulsados del sistema económico, condenados a vivir como parásitos a su pesar, y que además están enteramente desprovistos tanto de experiencia como de cultura política. Un partido así puede propagar sentimientos de rebelión, peor no proponerse la revolución" (2007, p. 416). El Partido Comunista Alemán no es una organización de obreros alemanes que buscan la transformación del régimen, más bien constituye "una organización de propaganda en manos de la burocracia del Estado ruso" (p. 419).
} 
del propio Trotsky, no tiene del partido más que el nombre; en lugar de soviets, sindicatos y cooperativas que funcionen democráticamente y dirijan la vida económica y política, organismos que llevan a decir verdad el mismo nombre pero reducidos a simples aparatos administrativos; en lugar del pueblo armado y organizado [...], un ejército permanente, una policía no controlada y cien veces mejor armada que la del zar; por último, y sobre todo, en lugar de funcionarios elegidos, siempre controlados, siempre revocables, que deberían asegurar el gobierno esperando el momento en que "hasta las cocineras aprenderían a gobernar el Estado", una burocracia permanente, irresponsable, [...] que posee, por la concentración en sus manos de todos los poderes económicos y políticos, un poder hasta ahora desconocido en la historia (p. 82).

Descartes decía que un reloj descompuesto no es una excepción a las reglas del reloj, sino un mecanismo que obedece a sus propias leyes; de igual forma la URSS no es un Estado obrero con "deformaciones burocráticas", es un mecanismo social diferente donde, la vida económica, política e intelectual, dependen enteramente de una administración centralizada: "La idea según la cual el régimen estalinista constituiría una simple transición, sea hacia el capitalismo, sea hacia el socialismo, parece igualmente arbitraria" (p. 83).

Ante esta situación, el deber se nos impone: "Nada en el mundo puede impedirnos ser lúcidos" (p. 98). Hay que mirar de frente la realidad y preguntar si el sucesor del régimen capitalista no será, en lugar de la asociación libre de productores, un nuevo sistema -como la URSS lo muestrade opresión. Los resultados de la revolución, y lo que por ésta se entiende serán duramente cuestionados por Weil.

Una de las principales críticas que Weil hace radica en el hecho que la revolución y el movimiento revolucionario están rodeado de mitos colectivos, los revolucionarios se cuentan a sí mismos historias fantásticas que les impiden ver la realidad. En febrero de 1933, Simone Weil le escribe a su amigo Thévenon: "[...] me niego a admitir cualquiera de estas nociones [comunismo, Partido, revolución] convertidas antes de la guerra en artículos de fe, sin nunca haberse analizado 
con seriedad [...] Me asfixio en este movimiento revolucionario de ojos vendados..." (Pétrement, 1997, p. 239).

\section{II) Crítica al concepto tradicional de la revolución}

En el texto que Simone Weil escribe para la revista La Critique Sociale titulado Reflexiones sobre la guerra (1933), la pensadora francesa señala que las ideas contemporáneas sobre revolución tienen su origen en las revueltas sociales de 1792, 1793 y 1794. De estos años data la concepción de guerra revolucionaria, defensiva y ofensiva no solo como forma legítima sino como "una de las formas más gloriosas de la lucha de las masas trabajadoras levantadas en contra de los opresores" (2007, p. 326), concepción que es muy común a la tradición marxista y a los revolucionarios de los últimos años. La revolución es entendida por la tradición como una revuelta social que utiliza las armas para obtener el poder, una vez que éste se ha conquistado, es posible modificar los regímenes de producción y por ende liberar a los trabajadores. Weil cree que es fundamental examinar esta extraña idea de revolución.

En primer lugar, esta palabra se encuentra llena de imaginarios colectivos, posee una excesiva carga de esperanza, después del nacimiento de la URSS, se ha pronunciado con demasiada frecuencia. Y aunque en teoría se debiera estar en "pleno periodo revolucionario [...] todo sucede como si el movimiento revolucionario decayera con el régimen que aspira a destruir" (Weil, 2015 p. 24). Ni siquiera el Estado que surgió de la revolución de octubre ha cumplido con su objetivo principal, la liberación obrera.

Por ello, uno de los deberes más importantes que se nos impone es el de tener suficiente valor intelectual como para preguntarnos si el término revolución es algo más que una palabra, si tiene un contenido preciso, si no es, sencillamente, una de las numerosas mentiras suscitadas dentro del régimen capitalista y que la crisis actual nos hace el favor de disipar ( $\mathrm{p} 25$ ). 
La revolución, según Weil, carece de sentido porque desea compensar todos los sufrimientos causados al pretender vengar el pasado y remediar las desdichas presentes, pero tan solo es una palabra por la que se mata, se muere e incluso se envían las masas populares a la muerte. Esta palabra mágica "encierra" la solución de todos los problemas indisolubles. La revolución es casi como un milagro, se desea su llegada del cielo, todos la esperan con ahínco, aunque nunca se pregunta quién la hará:

El obrero al que, en la fábrica [...] se le hace el tiempo largo, o el que no se cree hecho para el trabajo manual, o el que es perseguido por el jefe o sufre a la salida [...] piensa en la revolución. El pequeño comerciante desdichado, el rentista arruinado, vuelven los ojos hacia la revolución. El adolescente burgués en rebelión contra el ambiente familiar [...], el intelectual deseoso de aventuras y que se aburre, sueña con la revolución. La mayoría de aquellos que desean vivamente la libertad, la igualdad, el bienestar general, que sufren de ver miserias e injusticias, esperan una revolución (2007, p. 124. Las cursivas son mías).

Para analizar y destruir el misticismo que rodea al concepto de revolución, Weil pregunta sobre la validez de los medios de los que ésta se sirve. En opinión de la pensadora francesa, una revolución que utiliza la guerra para cumplir su objetivo está condenada al fracaso, pues puede sucumbir bajo los golpes de una contra revolución o ser ella misma una contra revolución por el propio mecanismo de la lucha militar. En este sentido, surge una importante cuestión: ¿Puede una revolución evitar la guerra?

Por otro lado, es absurdo creer que de una revolución violenta nazca un régimen de libertad, puesto que una lucha que toma como medio de acción la guerra hace que se combata una opresión bárbara con el peso de una opresión aún más bárbara; en definitiva, solo se extiende más el régimen que se desea suprimir. Para Weil, la violencia siempre desemboca en esclavitud, por ello la liberación de los obreros no puede operarse desde la revolución como acción bélica.

Otro de los problemas más acuciantes de la revolución, es que se trata de un movimiento de masas; pese a que Rosa de Luxemburgo confiaba plenamente en su espontaneidad, Weil cree que 
las masas "no plantean problemas, no los resuelven; por consiguiente, ni organizan ni construyen" (p. 125). Ellas mismas están impregnadas de los defectos del régimen que sufren. "Sus aspiraciones llevan la marca del régimen" (Ibíd.), es imposible que de las masas surja, 'espontáneamente', algo distinto al régimen que las ha formado "o más bien deformado" (p. 125).

Las colectividades presentan otro grave problema, ellas mismas segregan imaginarios, mitos que les permiten movilizarse hacia un objetivo en común; por ejemplo, el Partido Comunista está lleno no solo de fantasías sino de rituales pseudo religiosos. Weil, inspirada en Platón, afirma que todo grupo que intenta actuar es un gran animal y ahí donde se apaga el pensamiento siempre reina la imaginación. Las colectividades en la revolución oscurecen su motivo principal, la transformación social.

Al ser las masas tan desorganizadas y dirigirse por fantasías, es necesario que alguien lidere el movimiento. Por ello se necesita de un guía, y aquí nace el siguiente problema de la revolución, la burocracia. Ni siquiera en el movimiento revolucionario, los obreros se encuentran organizados de manera independiente. Un claro de ejemplo de esto es la revolución de octubre, el partido aparentemente revolucionario- asumió la vanguardia de los obreros; pese a que el objetivo principal era destruir la maquinaria con la que la realeza dirigía a la Rusia zarista, en realidad solo reforzó la máquina burocrática, militar y policiaca, centralizando la vida política, económica e intelectual en la administración estatal cuya dirección pertenece únicamente al partido.

La cuestión principal de la revolución no debe ser quién ocupará el puesto de mando; es fundamental crear una organización donde los obreros, y solamente ellos, dirijan la transición, sin recurrir a un aparato burocrático, ya que éste siempre es perjudicial:

La guerra revolucionaria es la tumba de la revolución y lo seguirá siendo mientras no dé a los propios soldados, o más bien a los ciudadanos armados, el medio de hacer la guerra sin aparato dirigente, sin presión policial, sin jurisdicción de excepción, sin penas para los desertores (p. 332. Las cursivas son mías). 
Por otro lado, la historia que se encuentra en los manuales escolares nos han enseñado que las revoluciones violentas son el parteaguas entre un periodo histórico y otro. Por ejemplo, se cree que el Imperio Romano cayó tras las invasiones bárbaras o que la realeza francesa fue derrocada por la burguesía en 1789. Sin embargo, Weil afirma que, en el caso de Roma, no hubo ninguna sustitución violenta, de hecho, en el propio Imperio los bárbaros ya ocupaban puestos importantes mientras los romanos solo iban tomando puestos honoríficos o subalternos. Lo mismo sucedió en Francia, cuando un siglo antes de la revolución, los burgueses ocuparon las funciones superiores del Estado y la nobleza, poco a poco, alcanzó un nivel casi parasitario:

Cuando parece que una lucha cruenta sustituye a un régimen por otro, esta lucha es en realidad una consagración de una transformación de la que ya se ha realizado más de la mitad [...] Las luchas violentas cuando se producen, y no se producen siempre, no desempeñan más que el papel de balanzas; dan el poder a aquellos que ya lo tienen ( $p$. 127).

Weil señala que la idea de revolución como transformación social categórica resulta inocua, pues mucho antes de la revuelta social, las transformaciones sociales ya están hechas o casi hechas: ¿cómo es posible que haya una ruptura total en la vida social, puesto que hay que comer, vestir, producir, mandar y obedecer todos los días? Es bajo un régimen que aparenta ser estable como se van produciendo lentamente las transformaciones en las relaciones sociales. En este sentido la revolución entendida como revuelta social violenta resulta gratuita; incluso, es posible que un cambio en el régimen de producción y las relaciones sociales pueda gestarse sin ella.

La crítica weiliana al concepto tradicional de revolución también analiza el andamiaje teórico de ésta, el cual -según la pensadora- se encuentra directamente en Karl Marx: "quienes han experimentado la necesidad de apuntar sus sentimientos revolucionarios con concepciones rigurosas han encontrado o han querido encontrar estas concepciones en Marx" (Weil, 2015, p. 25). Fiel al principio cartesiano de no aceptar nada sin antes no haber dudado de ello, Weil se dispone a revisar cuidadosamente las ideas que, según ella, son las venas que alimentan el ideal 
revolucionario de Marx: el desarrollo de las fuerzas productivas y la idea de la técnica al servicio de la humanidad.

Marx demostró a través de su teoría de las fuerzas productivas, la necesidad inevitable de una transformación social en la cual la opresión sería abolida definitivamente. El actual sistema de producción, el capitalismo, es el resultado de una serie de revoluciones en los modos de producción que ya no cabían en las relaciones sociales del sistema feudal:

En un determinado nivel de desarrollo de estos medios de producción y de cambio, ya no se correspondían [...] las relaciones feudales de propiedad con las fuerzas productivas en pleno desarrollo. Obstaculizaban la producción en vez de favorecerla. Se transformaban en otros obstáculos. Era preciso romperlos y se rompieron (Marx \& Engels, 2007, p. 16. Las cursivas son mías)

La historia, de acuerdo al joven Marx, de la industria y del comercio es la historia de la rebelión de las fuerzas productivas modernas contra las relaciones modernas de producción. Para comprender esta idea, es preciso aclarar que las fuerzas productivas determinan las relaciones de producción, éstas a su vez son la base de la superestructura jurídica, política e ideológica de la sociedad. En consecuencia, cuando las fuerzas productivas cambian también lo hacen las relaciones de producción y, por ende, las superestructuras.

En cierta fase de su desarrollo, las fuerzas productivas materiales de la sociedad entran en contradicción con las relaciones de producción existentes, o bien- lo que no es más que su expresión jurídica- con las relaciones de propiedad en el seno de las cuales se han desarrollado hasta ese entonces. Estas relaciones -como ya lo mencionamos- se convierten en trabas del desarrollo de las fuerzas productivas y entonces "se abre una época de revolución social. Al cambiar la base económica, se transforma más o menos rápidamente toda la superestructura inmersa" (Marx, 1989, p. 8).

El filósofo teutón cree que una formación social no desaparece antes de que se desarrollen las fuerzas productivas que caben dentro de ella. De igual forma, no aparecen relaciones nuevas de 
producción sin que hayan madurado las condiciones materiales para su existencia. Es así como el pensador alemán desarrolla su teoría de las fuerzas productivas y su importancia en los cambios sociales.

A partir de esta teoría, Marx analiza cuidadosamente su contexto histórico y concluye que las relaciones de producción burguesas son la última forma antagónica del proceso de producción, al mismo tiempo, estas formas de producción han otorgado las condiciones materiales para resolver dicho antagonismo, "con esta formación social se cierra, pues, la prehistoria de la sociedad humana" (p.8) y se abre la posibilidad de comenzar una nueva etapa, la dictadura del proletariado:

Las fuerzas productivas de que dispone [la burguesía] ya no le sirven para fomentar la civilización burguesa y las relaciones burguesas de propiedad. Todo lo contrario, se han convertido en demasiado poderosas para estas relaciones que les obstaculizan y cuando superan este impedimento, desorganizan toda la sociedad burguesa y ponen en peligro la existencia de la propiedad burguesa (Marx \& Engels, 2007, p. 17).

La burguesía misma ha construido a sus sepultureros, la clase obrera; la victoria del proletariado es inevitable, éstos -según Marx- poco a poco arrancarán el capital de la clase dominante, poco a poco se centralizarán todos los instrumentos de producción en manos del Estado, poco a poco aumentará la cantidad de fuerzas productivas. La transición por medio de la revolución comunista será violenta; es preciso no tener miedo, pues lo único que se perderá son las cadenas, por el contrario, un mundo entero se puede ganar.

La crítica del marxismo que Weil realiza en su texto Reflexiones sobre las causas de la libertad y la opresión social (1934) gira en torno al papel que juega la revolución en los cambios sociales. Como ya hemos visto, las fuerzas productivas se desarrollan con cada régimen hasta que no caben dentro de él, se modifican las relaciones de producción y un nuevo régimen social surge. En este contexto "la tarea de las revoluciones consiste esencialmente en la emancipación no de los hombres, sino de las fuerzas productivas" (Weil, 2015, p. 28). 
Marx augura un periodo en la historia (no muy lejano) en el que las fuerzas productivas se liberarán del capitalismo, para ese momento se encontrarán en una fase muy avanzada de su desarrollo que permitirán producir con un esfuerzo mínimo; así la técnica -sin los lastres del capitalismo- ofrecerá a los hombres el ocio suficiente para desarrollar cada una de sus facultades. El desarrollo ulterior de la técnica aligerará progresivamente el peso de la necesidad material y de la coacción social hasta que la humanidad alcanzase un estadio paradisiaco similar al de Adán y Eva.

Estas ideas, para Simone Weil, son cuestionables. Primero, Marx no explica por qué las fuerzas productivas tienden a un desarrollo infinito, así mismo, no queda claro por qué si las instituciones sociales se oponen al desarrollo de las fuerzas productivas, éstas siempre salen victoriosas. Marx admite, implícitamente que, las fuerzas de producción poseen una virtud secreta que les permite superar los obstáculos. Las revoluciones, de acuerdo al pensamiento de Marx, suceden cuando ya prácticamente todo por hacer ya está hecho, cuando el desarrollo de las fuerzas productivas ya no cabe dentro de las instituciones. En suma, para Weil, la doctrina de las fuerzas productivas de Marx -en la cual reposa su concepción de revolución- carece absolutamente de carácter científico.

La filósofa francesa señala que parte de este problema se encuentra en los orígenes hegelianos del pensamiento marxiano. El pensador teutón concibe la historia atribuyéndole a la materia, lo que Hegel le atribuyó al espíritu, una perpetua aspiración a lo mejor. Para Weil, la gran industria hizo de las fuerzas de producción una divinidad religiosa cuya influencia alcanzó a Marx, demostrando, paradójicamente, la tesis del pensador alemán sobre la subordinación del pensamiento a las condiciones económicas.

Por otro lado, Weil cuestiona la capacidad de la técnica moderna para asegurar el bienestar y ocio que augura Marx. Así mismo, le parece inocuo pensar que la técnica crecerá de forma ilimitada permitiendo, a su vez, un crecimiento ilimitado del rendimiento de trabajo. Empero, en el capitalismo, y parece también que, en el régimen ruso, esta cuestión se aceptó como dogma de fe, 
pues como lo muestra la historia de los últimos tres siglos, la técnica se ha desarrollado a velocidades insospechadas. Lo cual no quiere decir que este desarrollo se mantenga al mismo ritmo.

Para construir una teoría sobre el desarrollo ilimitado de la técnica es necesario tener en cuenta las siguientes cuestiones que el pensador teutón no tuvo presentes: en qué consiste el progreso técnico, qué factores intervienen en él y por qué, bajo el nombre de progreso técnico, se confunden procedimientos completamente diferentes y que ofrecen diferentes posibilidades de desarrollo. "Únicamente la embriaguez producida por la rapidez del progreso técnico ha hecho nacer la loca idea de que el trabajo podría llegar a ser superfluo algún día” (p. 39).

Weil cierra su análisis del marxismo afirmando que el pensador alemán solo se centró en los aspectos económicos de la opresión social, la explotación y la plusvalía. Por eso creía que la colectivización de los medios de producción permitiría la erradicación de la opresión; sin embargo, como el mismo Marx afirmó, la revolución socialista no puede realizarse en todas partes a la vez, cuando ésta triunfa es necesario aumentar la producción debido a que el socialismo en un solo país podría debilitar su economía y volverlo más débil que otras naciones. La Revolución Rusa es el mejor ejemplo de esta situación, ahí se incrementó la necesidad de explotar y oprimir a los trabajadores para no perecer, aunque se trata de un régimen completamente distinto al capitalismo, la opresión se mantiene con vida colocando su aplastante peso sobre los obreros. La opinión respecto al desarrollo de la técnica y la forma en la que ésta aligeraría el proceso de producción son ideas que también carecen de sustento teórico.

En conclusión, la "etapa superior del comunismo", considerada por Marx como la meta de la evolución social, es una utopía absolutamente análoga a la del movimiento perpetuo. Y la revolución solo ha sido el medio por el cual se ha pretendido llegar a ese paradisiaco estado:

En nombre de esa utopía los revolucionarios han derramado sangre; mejor dicho, han derramado su sangre en nombre o de esta utopía o de la creencia, igualmente utópica, en que el actual sistema de producción podría ponerse, por simple decreto, al servicio de la sociedad de los hombres libres e iguales (p. 39). 


\section{III) Reivindicación del espíritu rebelde}

Aunque Simone Weil es sumamente crítica con el concepto tradicional de revolución, ella sigue creyendo firmemente en la posibilidad de una transformación social. El primer paso para lograrlo, que junto a la pensadora hemos dado ya, es la develación de las mentiras que alimentan el mito revolucionario. Para la filósofa francesa la revolución no es:

[...] una religión para la que un mal creyente sea preferible a un incrédulo. Es una tarea práctica. No se puede ser revolucionario solo de palabra, del mismo modo que no se puede ser albañil o herrero solo de palabra. Solo es revolucionaria la acción que prepara una transformación del régimen; o también los analistas y las consignas que no simplemente predican, sino que preparan esa acción (Weil, 2007, p 463. Las cursivas son mías).

Pese a que la historia y, sobre todo, el régimen ruso, han hecho de la revolución un mito que se mide por la cantidad de sangre derramada en ella, Weil no desespera. Sus palabras pueden resultar dolorosas y para algunos, pesimistas, pero son necesarias. La filósofa francesa cree que una transformación social efectiva solo puede comenzar cuando se eliminan las fantasías y se estudia con seriedad las condiciones de existencia de los trabajadores, los verdaderos protagonistas. En 1935 le escribe a su amiga Albertine Thévenon:

Solo que cuando pienso que los grrrandes [sic] jefes bolcheviques pretendían crear una clase obrera libre y que seguramente ninguno de ellos -Trotsky seguramente que no y Lenin creo que tampoco- había puesto los pies en una fábrica y por consiguiente no tenía la más ligera idea de las condiciones reales que determinan la servidumbre o la libertad de los obreros... la política me parece una broma siniestra (Weil, 2014, p. 42).

La exasperación, así como las revueltas que se dan sin conocer las causas de la opresión pueden favorecer a la demagogia fascista, e incluso, como lo muestra Rusia, fortalecen un aparato burocrático centralizado. El corazón de cualquier revolución se encuentra en los obreros mismos: 
"La emancipación de los trabajadores será obra de los propios trabajadores o no será" (Weil, 2007, p. 97) y hacia ahí hay que viajar. La verdadera acción revolucionaria solo puede basarse en el conocimiento del funcionamiento de la opresión social.

De esta manera, la tarea más importante es la de analizar cada una de las causas de la opresión para encontrar el método que permita suprimirlas completamente y -no como en el marxismo- de manera aparente. Sin este análisis previo solo se podría llegar a una transformación que implique beneficios a ciertas personas. La revolución solo puede ser dirigida por hombres conscientes y responsables.

Entre el esclarecimiento teórico y la lucha eficaz no hay ninguna contradicción; por el contrario, hay correlación: no se puede actuar sin saber lo que se quiere y sin conocer los medios por los que se puede llegar a obtener. Aunque nuestro tiempo en el mundo es limitado debemos invertirlo en la preparación para la acción: "En cualquier caso, la mayor desgracia para nosotros sería morir incapaces a la vez de triunfar y comprender" (p. 98).

En sus Reflexiones sobre las causas de la libertad y la opresión social, Weil busca las causas de la opresión fuera de los esquemas económicos. Y concluye que el problema no radica en la existencia de un régimen en específico, sino en una crisis de la sociedad misma. En la base de ésta se encuentra la técnica que, pese a lo que Marx creía, solo ha posado con más firmeza el peso de la opresión sobre los obreros.

Weil afirma que en la historia de la humanidad solo se han conocido dos tipos de opresión, el esclavismo o servidumbre que, era ejercida en nombre de la fuerza armada. La segunda, en nombre de la riqueza que se transforma en capital; es posible que les esté sucediendo una tercera clase: la opresión en nombre de la función.

El fenómeno que para Marx era el centro del capitalismo, la compra y venta de trabajo, se ha convertido en un factor subordinado en la opresión de los trabajadores. El momento decisivo no es cuando el obrero entra al mercado a vender-se, sino cuando traspasa el umbral de la fábrica. La 
opresión de los obreros asalariados, en la época de la gran industria, se convierte en un simple aspecto de las relaciones contenidas en la técnica de la producción.

La técnica moderna, en especial la racionalización (aplicación de la ciencia al trabajo) ha hecho que en la fábrica existan dos clases de hombres, "aquellos que ejecutan el trabajo sin tener en él [...] ninguna parte activa y aquellos que dirigen el trabajo sin ejecutar nada. Entre estas dos partes de la población de una empresa, la máquina constituye una barrera infranqueable" (p. 88. Las cursivas son mías).

A la oposición tradicional entre compradores y vendedores de la fuerza de trabajo, se le añade otra creada en el propio centro de producción: entre quienes disponen de la máquina y aquellos de los que la máquina dispone. La experiencia rusa ha mostrado que la primera oposición puede desaparecer sin que necesariamente lo haga la segunda.

La maquinaria, que en teoría- debiese aligerar el peso del trabajo, convierte al hombre en un accesorio a su servicio. Al repetir monótonamente la misma operación, el hombre no puede pensar o meditar sobre el trabajo que está realizando, pensar significa ir más lento: "Esta situación hace que el pensamiento se encoja, se retraiga lo mismo que la carne se retrae ante el bisturí. No se puede estar 'consciente'"' (Weil, 2014, p. 47).

La forma en la que están organizadas las fábricas constituye uno de los problemas más graves que tiene que enfrentar el revolucionario porque, en el seno de ella misma se genera el sentimiento de humillación:

Cuando una obrera se juzga víctima de una injusticia, va a quejarse. Pero es humillante, ya que no tiene ningún derecho y se encuentra a merced de la buena voluntad de los jefes, que deciden según el valor de la obrera y en gran medida según su fantasía (Leivovici, 2012, p. 67).

En la fábrica, la organización del trabajo oprime a los trabajadores:

La índole propiamente moderna de la estructura técnica del modo de producción capitalista reside en el hecho de que la opresión se ejerce en adelante directamente por 
intermedio de la organización del trabajo: la mecanización no tiene solamente por función permitir el incremento de la plusvalía, ella transporta la esclavitud al mismo acto de trabajo, que se convierte directamente en un dispositivo de degradación de aquel que lo ejerce (p. 90).

Esta situación permite comprender por qué para Weil el término correcto no es el de explotación sino opresión:

Si mañana se echa a los patronos, si se colectivizan las fábricas, eso no cambiará en nada el problema fundamental que consiste en lo que es necesario para sacar el mayor número posible de productos no es necesariamente lo que puede satisfacer a los hombres que trabajan en la fábrica (Weil, 2014, p. 227).

Para Weil, la verdadera contradicción que mina las sociedades capitalistas no se da, como Marx pensó, entre las fuerzas productivas y las relaciones de producción. Sino entre el desarrollo de fuerzas productivas y condiciones materiales de la producción. El desarrollo de éstas ha creado tres capas sociales muy distintas: los obreros, instrumentos pasivos de la empresa, los capitalistas, cuyo poder radica en el régimen económico y los administradores, que se apoyan en el desarrollo de una técnica cuya evolución aumenta progresivamente su poder.

Aunque Marx demostró cómo una revolución puede expropiar a los expropiadores, no mostró cómo un modo de producción basado en la subordinación de los que ejecutan a los que coordinan podría no producir de manera automática una estructura social definida por la dictadura de una nueva casta burocrática:

Habrá socialismo cuando la función dominante sea el trabajo productivo mismo; pero eso es lo que no se puede producir mientras perdure un sistema de producción en el que el trabajo propiamente dicho se encuentra subordinado, por medio de la máquina, a la función consistente en coordinar los trabajos. Ninguna expropiación puede resolver este problema, contra el que se estrelló el heroísmo de los obreros rusos (Weil, 2007, p. 91). 
En diciembre de 1934, Weil comienza un proyecto que la enfrenta con la vida real. Con el propósito de poner a prueba su propia teoría, trabaja durante casi un año en distintas fábricas. El resultado queda grabado en su Diario de fábrica, en estas páginas se da testimonio de la opresión que se posa en los hombros de los trabajadores, opresión causada en algunos momentos por los jefes: “Mouquet le ha dicho 'Tiene usted los cabellos tan largos como el cuerpo'. Estaba humillada, humillada. Hubiera querido contestar groseramente. 'No se puede contestar' [...] Se cuentan sus palabras humillantes: '¿Nunca ha estado usted en celo?’” (Weil, 2012, p. 83).

En el centro de trabajo uno se siente esclavo: "Sin embargo me agoto, por la noche me siento por primera vez, machacada de cansancio, como antes de irme a Montana; sensación de comenzar de nuevo a resbalar al estado de bestia de carga" (p. 89). Y las máquinas alimentan este sentimiento: "He intentado ir rápida, pero continuamente me sorprendía cayendo en la ensoñación [...] Cansada, sobre todo a la salida [...] Me siento esclava ante mi máquina" (p. 93).

En la fábrica, el pensamiento no existe:

El agotamiento acaba por hacerme olvidar las verdaderas razones de mi estancia en la fábrica, convierte en casi invencible para mí la tentación más fuerte que comporta esta vida: la de no pensar, único medio de no sufrir. Solo el sábado por la tarde y el domingo, cuando recupero recuerdos, fragmentos de ideas, me acuerdo de que soy también un ser pensante. Pavor que se apodera de mí al constatar la dependencia en que me encuentro respecto de las circunstancias externas: bastaría con que me obligaran una vez a un trabajo sin descanso semanal -lo que, después de todo, siempre es posible- y me convertiría en una bestia de carga, dócil y resignada (al menos para mí). Solo el sentimiento de fraternidad, la indignación ante las injusticias infligidas a otros, subsisten intactos; ¿pero hasta qué punto aguantaría todo esto a la larga? No estoy lejos de concluir que la salvación del alma de un obrero depende en primer lugar de su constitución física. No veo cómo los que no son recios pueden evitar caer en una forma cualquiera de desesperación -borrachera, o vagabundeo, o crimen, o simplemente, y mucho más a 
menudo, embrutecimiento- (¿`y la religión?) (¿y la revolución?) (Weil, 2014, p. 80. El subrayado es del texto).

En este contexto, los trabajadores se sienten solos:

La rebelión es imposible, salvo por destellos [...] ¿contra qué? Estamos solos con nuestro trabajo, no podríamos revolvernos más que contra él [...] Somos como los caballos que se hieren a sí mismos cuando tiran del bocado -y agachamos la cabeza. Se pierde incluso la conciencia de esta situación, se le sufre, eso es todo. Cualquier despertar del pensamiento es entonces doloroso ( $p$ 81).

La fábrica debería ser el nido donde se gestan los sentimientos revolucionarios, pero la experiencia de Weil nos muestra lo contrario, en ese lugar se germina la sumisión e incluso el desprecio por la vida:

Yo, a pesar de mi cansancio, tengo tal necesidad de aire fresco que voy a pie hasta el Sena; ahí me siento en la orilla, en una piedra, triste y agotada y con el corazón oprimido hasta la rabia impotente, sintiéndome vaciada de toda mi sustancia vital; me pregunto si, en caso de que fuera condenada a esta vida, llegaría a cruzar todos los días el Sena sin lanzarme alguna vez en él (p 105).

De acuerdo con su biógrafa, Simone Pétrement (1997), la experiencia en la fábrica le permitió reforzar la idea de que la esclavitud de los trabajadores no radica en la existencia de un régimen económico específico, sino que está íntimamente ligada a las condiciones de trabajo (técnica, máquinas, suspensión del pensamiento, humillación). En la historia de la humanidad, las formas de esclavitud dependían de las circunstancias, sin embargo, en el capitalismo ésta viene del propio trabajo.

Los duros meses que pasa Weil en la fábrica le ayudan a describir los problemas de la condición obrera; el principal: en el capitalismo los trabajadores no cuentan para nada: 
¿Ganado con esta experiencia? El sentimiento de que no poseo ningún derecho, cualquiera que sea, a lo que sea (atención a no perderlo). La capacidad de bastarme moralmente a mí misma, de vivir en este estado de humillación latente, perpetua, sin sentirme humillada a mis propios ojos; de disfrutar intensamente cada instante de libertad o de camaradería, como si fuera a ser eterno. Un contacto directo con la vida...

He estado a punto de romperme. Casi lo he estado -mi coraje, el sentimiento de dignidad han sido poco a poco vencidos durante un periodo cuyo periodo me humillaría a no ser porque, hablando con propiedad, no he conservado el recuerdo. Me levantaba con angustia, iba a la fábrica con temor; trabajaba como una esclava; la pausa de mediodía era un desgarro; vuelta a las $5 \mathrm{~h} 3 / 4$, preocupada en seguida por dormir bastante (lo que no hacía) y por despertarme lo bastante temprano. El tiempo era un peso intolerable. El temor -el miedo- de lo que iba a seguir no dejaba de oprimirme el corazón más que el sábado por la tarde y el domingo por la mañana. Y el objeto de temor eran las órdenes.

El sentimiento de dignidad personal tal como ha sido fabricado por la sociedad está roto. Hay que forjarse otro (iaunque el agotamiento prive a la conciencia de su propia facultad de pensar!). Esforzarme por conservar ese otro.

Finalmente se da uno cuenta de su propia importancia.

La clase de aquellos que no cuentan -en ninguna situación- a los ojos de nadie... y que no contarán nunca, pase lo que pase (a pesar del último verso de la primera estrofa de la Internacional) (Pétrement, 1997, p. 130. Las cursivas son mías).

El objetivo de la revolución comienza a ser claro, ésta no puede ser una lucha armada, violenta, que sacrifique miles de vidas inocentes. En primer lugar, la revolución gira en torno a la glorificación del trabajo productivo, actividad suprema del hombre. Es necesario crear una sociedad en la que el trabajo ponga en juego todas las facultades del ser humano. El hombre que trabaje debe estar en primera fila porque el trabajo es la plenitud de la grandeza humana.

Por ello, las condiciones de trabajo son sumamente importantes. El movimiento revolucionario también debe centrase en una transformación técnica, revolución significa crear las 
condiciones sociales que transformen los medios de producción en instrumentos de trabajo libre y asociado. El trabajador debe tener dominio de sus condiciones de trabajo y los trabajos deben estar coordinados sin que uno de subordine a otro.

\section{IV) El trabajo manual como el corazón de la revolución}

En el capítulo $\mathrm{V}$ del primer tomo de su Opus Magnum, Marx define el trabajo como un proceso entre el hombre y la naturaleza en el que el primero media, controla y regula su metabolismo con el segundo. El hombre, a través del trabajo pone en movimiento sus fuerzas con el propósito de apoderarse de los materiales que existen en el mundo y así convertirlos en útiles para la vida propia.

Por medio del trabajo, el hombre no solo transforma la materia, sino que se transforma a sí mismo, desarrollando potencias que dormitaban en él. Marx define el trabajo como aquello que pertenece exclusivamente al hombre, aunque en la naturaleza, los animales ejecutan ciertos movimientos que podrían asemejar al trabajo, el pensador teutón afirma que solo el ser humano tiene la capacidad de pensar, y el pensamiento es fundamental para la realización del trabajo:

[...] una araña ejecuta operaciones que recuerdan a las de un tejedor y una abeja avergonzaría, por la construcción de las celdillas de su panal, a más de un maestro albañil. Pero lo que distingue ventajosamente al peor maestro albañil de la mejor abeja, es que el primero ha modelado la celdilla en su cabeza antes de construirla en la cera. Al consumarse el proceso de trabajo surge un resultado que al comienzo de aquél ya existía en la imaginación del obrero o sea, idealmente. El obrero no solo efectúa un cambio de forma de lo natural; en lo natural, al mismo tiempo, efectiviza su propio objetivo, objetivo que él sabe que determina como una ley, el modo y manera de su accionar y al que tiene que subordinar su voluntad (Marx, 1989, p. 216. Las cursivas son el texto). 
El obrero no solo utiliza su cuerpo durante la ejecución del trabajo, sino que orienta su voluntad a un fin determinado, a esta orientación Marx la llama "atención". En suma, el trabajo pone en juego las fuerzas físicas y espirituales del hombre, por eso esta actividad solo le pertenece a él.

En este punto, Simone Weil se encuentra muy cercana a Marx. La pensadora francesa, hace hincapié en el hecho de que el trabajo es la unión del pensamiento y la acción. Lectora de Descartes, se enfrenta al problema de la división sustancial ofreciendo una novedosa solución:

[...] yo soy siempre dos: por una parte el ser pasivo objeto del mundo, por otra, el ser activo que lo aprehende. Cierto que yo no puedo unirlos directamente, puesto que en eso consiste precisamente la acción [...] para llamarla con su verdadero nombre, el trabajo (Weil, 2006, p. 79-80).

De acuerdo a Simone Pétrement (1997), el trabajo ocupó el centro de las reflexiones weilianas en sus primeros trabajos escolares. En 1929 definió al trabajo como una actividad ajena a las emociones y deseos que experimentan los seres humanos. Cuando, por ejemplo, se tiende la mano hacia algo que se desea no se está realizando un trabajo, hay trabajo a partir del momento en el que, para procurarnos aquello que nos interesa debemos ir hacia lo que no nos interesa.

Para la joven Weil, el trabajo es una acción compartida, compuesta de partes relacionadas y distintas entre sí (pensamiento y acción): "Solo el trabajo puede relacionar entre sí las emociones que experimento y la extensión que a través de ellas capto como constituyente de la existencia antagonista" (2007, p. 117). Con esta teoría, afirma Pétrement, Weil desea glorificar al obrero, pues solo a través del trabajo, el hombre aprehende el mundo.

Es, como afirmó Marx, la función esencial de los hombres. En primer lugar nos recuerda que estamos sometidos a una necesidad y que dicha necesidad es la esencia de la condición humana. A través del trabajo se mide la resistencia que la vida material nos coloca, es el enfrentamiento del ser humano con la materia, por ello se compromete al cuerpo y al espíritu en atención activa:

La razón [de la importancia del trabajo] sería, por lo tanto, la capacidad de convertir los obstáculos en materia de trabajo, y éste, en consecuencia, será la actividad mediante la 
cual el ser dotado de razón consigue asimilarlos; de esta forma el ser humano establece un intercambio de energía con el medio en el que vive (Revilla, 2011, p. 44).

En segundo lugar, el trabajo nos permite conocer cómo son las cosas fuera de nosotros, de igual forma pone a prueba la existencia del pensamiento y la influencia que éste tiene sobre el mundo material. Weil no habla de cualquier trabajo, sino del manual ya que es el que se encuentra mayormente gobernado por la necesidad, en él existe un irreductible elemento de servidumbre.

En tercer lugar, el trabajo manual es fuente de libertad. Weil cree, al igual que Marx, que mediante el trabajo se unen el pensamiento y la acción, y solo aquellas acciones que provengan del pensamiento pueden llamarse libres: "La libertad verdadera no se define por una relación entre el deseo y la satisfacción, sino por una relación entre el pensamiento y la acción; sería completamente libre el hombre cuyas acciones procediesen, todas, de un juicio previo" (2015, p. 66). Por eso el único modo de producción verdaderamente libre sería aquel en el que el pensamiento metódico estuviese en práctica a lo largo del trabajo.

En el capitalismo, el trabajo se divide para producir con velocidad. Esta división convierte en elementos necesarios de la fábrica, el orden y la dirección. Por un lado, hay una persona calificada para realizar esta labor y por el otro, personas que ejecutan las órdenes del primero. La desdicha en el trabajo, procede para Weil, no de los sufrimientos físicos que éste provoca, sino de los efectos sufridos en el ánimo por esta división. Los que mandan oprimen a los que ejecutan. En la fábrica todo -la actitud de los jefes, la organización misma del trabajo- está diseñado para "humillar".

Por humillación, Simone Weil entiende la suspensión del pensamiento. Proceso al cual ayuda la mecanización, que en el capitalismo tiene como objetivo aumentar la plusvalía pero que, al ser transportada al centro de trabajo, provoca esclavitud. La máquina piensa por el hombre mientras éste pasa a ser un simple accesorio de ella. El peor acto que se puede cometer contra un individuo es impedirle pensar, pues esto es lo único que le pertenece a la especie humana. 
Por eso, para Simone Weil, una revolución efectiva debe girar en torno a dos cuestiones fundamentales: reivindicación del trabajo manual como centro de la vida humana y la creación de una tecnología que ponga en práctica la reflexión metódica de los trabajadores. De esta forma se podrá crear una sociedad en la que el común de los hombres se encuentra obligado a pensar antes de actuar, una civilización plenamente humana que tendría al trabajo manual como valor supremo:

El trabajo manual debe llegar a ser el valor más alto no por su relación con lo que produce, sino por su relación con el hombre que lo lleva a cabo no debe ser objeto de honores o recompensas, sino constituir para cada ser humano, aquello de lo que, más esencialmente, tiene necesidad para que su vida tome por sí misma un sentido y un valor a sus propios ojos (p. 83).

\section{V) La revolución, amor por la vida}

Hemos descrito la forma en la que Weil despoja a la revolución de los mitos y las fantasías que le rodeaban. No se trata de una conmoción irracional sino de una tarea práctica que no se puede realizar con los ojos vendados; es un trabajo, que comienza con un deber: pensar, analizar los medios que se utilizarán y si éstos resultan inciertos o peligrosos, hay que replantearse nuevamente todo.

Como ya hemos visto, la revolución va más allá de una revuelta violenta, para erradicar la opresión que sufren los obreros es menester que ellos pierdan el sentimiento de inferioridad que se les imprime en la fábrica. Hay que elevarlos a sus propios ojos. Para esto la cultura y el conocimiento se convierten en las condiciones necesarias para una verdadera revolución. La desaparición de, lo que Marx llamaba, la degradante división entre el trabajo intelectual y el trabajo manual- tiene que ser una de las prioridades de la revolución para ello es necesario que los obreros puedan manejar el lenguaje y en especial, el lenguaje escrito.

Por otro lado, como ya lo habíamos dicho, la revolución también debe traer consigo mismo una profunda transformación técnica para que se restablezca el dominio del trabajador sobre las condiciones de trabajo. Por tanto, la revolución no solo se prepara mediante la elevación del nivel 
de vida, de cultura y educación de los obreros, asimismo, es imprescindible que se investigue la forma en la que se pueden organizar los trabajos sin que ninguno esté subordinado a otro. Para el revolucionario, el problema que se debe plantear no es la forma en la que se pueda derribar un gobierno, sino cómo encontrar un modo de organización tal que la revolución no resulte inútil.

La revolución no es una conmoción irracional, una catástrofe o la liberación de los instintos, se trata de una acción metódica cuyos estragos hay que limitar, es una moralidad superior. Ser revolucionario es favorecer mediante diversos actos aquello que pueda, directa e indirectamente, aliviar o levantar el peso que oprime a los obreros, ser revolucionario es rechazar las mentiras por medio de las que se disfraza o se disculpa la humillación de los trabajadores. Ser revolucionario es un ideal, un juicio de valor, una voluntad, y no una interpretación de la historia humana y del mecanismo social. El espíritu revolucionario, éste espíritu revolucionario, es tan antiguo como la propia opresión y debe durar tanto como ella, incluso más, pues, si ésta desaparece, él deberá subsistir para impedir que reaparezca; por último, el espíritu revolucionario, debe ser purificado de todas las aportaciones extrañas que puedan venir a disfrazarlo y alterarlo.

Influenciada por las figuras de Antígona y Rosa de Luxemburgo, para Simone Weil, la revolución recibe su razón de ser en el amor a la vida humana:

No se puede ser revolucionario sino se ama la vida. La revolución no puede dar un sentido a la vida humana [...] es una lucha contra todo lo que obstaculiza la vida. No tiene sentido más que como medio; si el fin perseguido es vano, el medio pierde su valor. De manera general, nada tiene valor desde el momento en que no lo tienen la vida humana (Weil, 2007, p. 103).

\section{Referencias:}

Leibovici, M. (2012), La injusticia social y las figuras del rechazo en Simone Weil. En V. Gerard (Ed.), Simone Weil, lecturas políticas (p. 79-100), Buenos Aires: Nueva visión.

Marx, K. \& Engels, F. (2007). El manifiesto del partido comunista; Barcelona: Ediciones Folio. Marx, K. (1989). Contribución a la crítica de la economía política; México: Editorial Progreso. 
Pétrement, S. (1997). Vida de Simone Weil, Madrid: Trotta.

Revilla, C. (2011). Vida y obra de Simone Weil, Madrid: Asociación Matritense de Mujeres Universitarias.

Weil, S. (2006). Sobre la ciencia, Buenos Aires: El cuenco de Plata, 2006.

Weil, S. (2007). Escritos históricos y políticos, Madrid: Trotta.

Weil, S. (2014). La condición obrera, Madrid: Trotta.

Weil, S. (2015). Reflexiones sobre las causas de la libertad y de la opresión social, Madrid: Trotta. G. 